\title{
INFLUÊNCIA DO TIPO DE ÓLEO UTILIZADO PARA FRITURA NA ESTABILIDADE DE AMÊNDOAS DE CASTANHA DE CAJU
}

\author{
JANICE RIBEIRO LIMA * \\ MARTA MARIA MARTINS SOUSA **
}

\begin{abstract}
Avaliou-se a influência do tipo de óleo utilizado para fritura na estabilidade de amêndoas de castanha de caju processadas. Foram empregados nos testes quatro tipos de óleos (soja, algodão, gordura vegetal hidrogenada e babaçu) com temperatura e tempo de fritura fixos. As amêndoas processadas foram avaliadas quanto às suas características físico-químicas, logo após o processamento e depois de quatro meses de armazenamento (embalagens de polietileno, temperatura ambiente), visando verificar o efeito do tipo de óleo no envelhecimento do produto. Foram realizados ainda testes sensoriais de ordenação/preferência, com o objetivo de determinar o tratamento (óleo utilizado) preferido. Os resultados indicaram que a gordura vegetal hidrogenada é mais adequada para a fritura de amêndoas de castanha de caju.
\end{abstract}

\section{INTRODUÇÃO}

A castanha, verdadeiro fruto do cajueiro, é constituída basicamente de três partes: a casca, a película e a amêndoa. O produto de maior expressão econômica do cajueiro é a amêndoa, parte comestível da castanha, que representa em média $30 \%$ de seu peso. A amêndoa da castanha de caju torrada e salgada constitui a principal forma de consumo, sendo usada no acompanhamento de coquetéis e como tira-gosto. A amêndoa torrada sem sal serve para a confecção de bolos, doces, bombons e chocolates, enriquecendo-Ihes o sabor e aspecto (11).

A produção mundial comercializável de amêndoas de castanha de caju está concentrada em apenas três países, Índia, Brasil e Vietnã, os quais são responsáveis por aproximadamente 92\% da produção (4). Segundo dados da FAO, em 1998, no mundo, foram exportadas 125 milhões de

\footnotetext{
* Pesquisadora da Embrapa Agroindústria Tropical, Fortaleza, CE. (e-mail: janice@cnpat.embrapa.br).

** Bolsista PIBIC, Embrapa Agroindústria Tropical, Fortaleza, CE.
} 
toneladas de amêndoas de castanhas de caju. Neste mesmo ano, o Brasil exportou aproximadamente 32 milhões de toneladas, com valor estimado de 142 milhões de dólares.

A amêndoa de castanha de caju produzida no Brasil constitui-se em produto de exportação, sendo $90 \%$ da produção destinada ao mercado internacional. As exportações de amêndoas de castanha de caju movimentam, em nível mundial, em torno de meio bilhão de dólares anualmente, ocupando o terceiro lugar entre as nozes (amêndoas comuns, avelãs, pecãs, macadâmias e outras) que participam deste mercado (3).

O elevado índice de amêndoas quebradas durante o processamento no Brasil, aliado ao fato de quase todo o volume exportado ser de amêndoas semi processadas (cruas), reduz o seu valor agregado (3).

As operações envolvidas no processamento de amêndoas de castanha de caju são basicamente o cozimento, a secagem, o corte, a decorticação, a despeliculagem, a classificação, a fritura e a embalagem. A etapa de fritura é crítica, pois exerce influência direta na qualidade e estabilidade das amêndoas de castanha de caju processadas. Durante a fritura ocorrem diversas reações complexas que produzem numerosos compostos de degradação. Estas reações acontecem em menor ou maior escala em função do óleo empregado no processo, da natureza do alimento que está sendo frito e das condições do processo de fritura.

A formação de odores e sabores estranhos em lipídios e alimentos que os contêm, geralmente descrita como rancidez, é seguramente uma das reações mais importantes de deterioração em alimentos. Os mecanismos através dos quais estas reações se processam foram estudados e detalhados por alguns autores (5, 6, 7 e 8). Existem várias formas de se avaliar o estado oxidativo de óleos ou de frações lipídicas dos alimentos. Dentre os testes mais utilizados estão o índice de acidez (rancidez hidrolítica), índice de peróxido e índice de anisidina (rancidez oxidativa). A oxidação pode causar a destruição de vitaminas, ácidos graxos, pigmentos e proteínas, mas o decréscimo das qualidades organolépticas é o efeito mais visível decorrente deste processo.

O objetivo deste trabalho foi avaliar a influência de diferentes tipos de óleo na estabilidade e aceitação de amêndoas de castanha de caju fritas. Devese salientar que o alto teor de gordura e baixo teor de umidade das amêndoas de castanha de caju fazem com que estes produtos sejam susceptíveis à oxidação e ao ganho de umidade.

\section{MATERIAL E MÉTODOS}

Foram utilizadas amêndoas de castanhas de caju, provenientes do campo experimental de Pacajus - CE, processadas de acordo com o fluxograma 
apresentado na Figura 1, sendo as amêndoas despeliculadas utilizadas nos testes de fritura.

\section{FIGURA 1 - FLUXOGRAMA DO PROCESSAMENTO DE AMÊNDOAS DE CASTANHA DE CAJU}

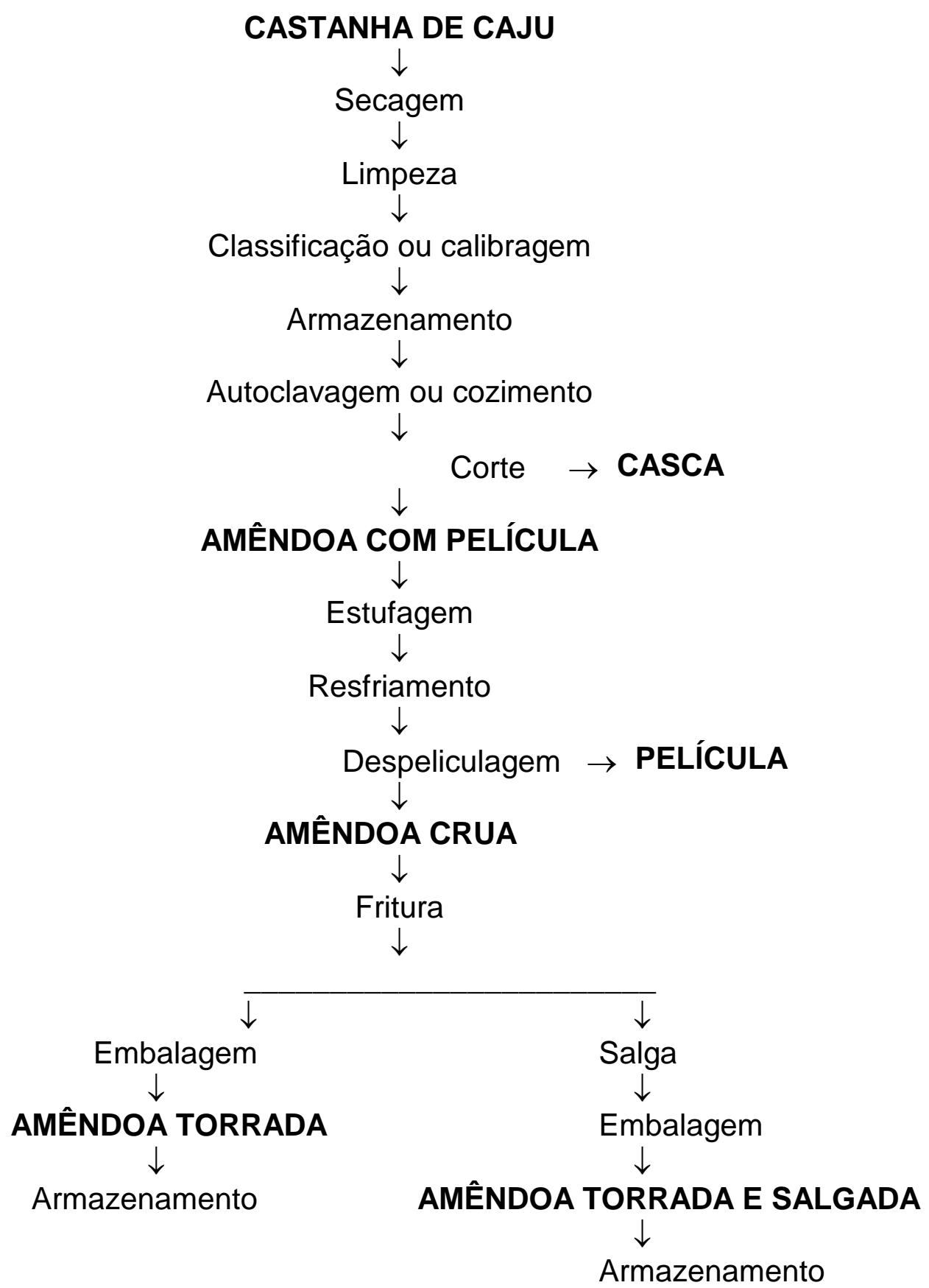

A fritura das amêndoas foi realizada em fritadeira elétrica, temperatura de $140 \pm 2 \stackrel{\circ}{ } \mathrm{C}$ por 2 minutos, empregando-se óleos de algodão, soja, babaçu e gordura vegetal hidrogenada. 
As amêndoas fritas foram avaliadas quanto às suas características físicoquímicas, logo após o processamento e depois de 4 meses de armazenamento (embalagens de polietileno, temperatura ambiente), mediante as seguintes determinações:

- Teor de lipídios totais, em aparelho Soxhlet, segundo o IAL, método $4.10(10)$;

- Teor de proteína bruta, de acordo com o método 955.04 da AOAC (1);

- Teor de cinzas, segundo a AOCS, método Ca 11-55 (2);

- Umidade e matéria volátil, conforme o método Ca 2c-25 da AOCS (2);

- Índice de peróxidos da fração lipídica, de acordo com a AOCS, método Cd 8-53 (2);

- Índice de acidez da fração lipídica, segundo a AOCS, método Ca 5a-40 (2).

Para interpretação dos resultados físico-químicos utilizou-se a análise de variância, sendo que os tratamentos foram comparados pelo teste de "Tukey" (teste de média) ao nível 0,05 de probabilidade.

Realizou-se ainda teste sensorial de ordenação/preferência (9), com 35 provadores não treinados, antes e após o armazenamento de 4 meses. Os provadores foram solicitados a provar e colocar as amostras de amêndoas de castanha de caju em ordem crescente de preferência, sendo utilizado o teste de "Friedman" para interpretação dos resultados.

\section{RESULTADOS E DISCUSSÃO}

$\mathrm{Na}$ avaliação físico-química o teor de cinzas (Tabela 1) não se alterou durante 0 armazenamento das amêndoas. Os valores no tempo zero variaram de 2,45 a 2,64\% e após 4 meses de armazenamento de 2,49 a $2,64 \%$.

\section{TABELA 1 - TEOR DE CINZAS (\%) EM AMÊNDOAS DE CASTANHA DE CAJU FRITAS EM DIFERENTES ÓLEOS}

\begin{tabular}{ccccc}
\hline $\begin{array}{c}\text { Tempo } \\
\text { (meses) }\end{array}$ & $\begin{array}{c}\text { Gordura Vegetal } \\
\text { Hidrogenada }\end{array}$ & $\begin{array}{c}\text { Óleo de } \\
\text { Algodão }\end{array}$ & $\begin{array}{c}\text { Óleo de } \\
\text { Babaçu }\end{array}$ & Óleo de Soja \\
\hline 0 & $2,64 \mathrm{~A}$ & $2,45 \mathrm{~A}$ & $2,51 \mathrm{~A}$ & $2,49 \mathrm{~A}$ \\
4 & $2,56 \mathrm{~A}$ & $2,49 \mathrm{~A}$ & $2,64 \mathrm{~A}$ & $2,53 \mathrm{~A}$ \\
\hline
\end{tabular}

Em cada coluna, médias seguidas pelas mesmas letras não diferem significativamente ao nível de $5 \%$ pelo teste de Tukey. 
A umidade (Tabela 2) aumentou durante o armazenamento, já que as embalagens utilizadas (polietileno) apresentaram pouca barreira ao vapor de água. Os valores observados de umidade antes do armazenamento variaram de 3,39 a $5,29 \%$ e após 4 meses de armazenamento de 6,65 a $9,96 \%$.

\section{TABELA 2 - TEOR DE UMIDADE (\%) EM AMÊNDOAS DE CASTANHA DE CAJU FRITAS EM DIFERENTES ÓLEOS}

\begin{tabular}{ccccc}
\hline $\begin{array}{c}\text { Tempo } \\
\text { (meses) }\end{array}$ & $\begin{array}{c}\text { Gordura Vegetal } \\
\text { Hidrogenada }\end{array}$ & $\begin{array}{c}\text { Óleo de } \\
\text { Algodão }\end{array}$ & $\begin{array}{c}\text { Óleo de } \\
\text { Babaçu }\end{array}$ & Óleo de Soja \\
\hline 0 & $3,39 \mathrm{~B}$ & $3,75 \mathrm{~B}$ & $3,75 \mathrm{~B}$ & $5,29 \mathrm{~B}$ \\
4 & $6,65 \mathrm{~A}$ & $7,07 \mathrm{~A}$ & $9,96 \mathrm{~A}$ & $8,25 \mathrm{~A}$ \\
\hline
\end{tabular}

Em cada coluna, médias seguidas pelas mesmas letras não diferem significativamente ao nível de $5 \%$ pelo teste de Tukey.

Os teores de proteína (Tabela 3 ) apresentaram pequenas alterações durante o armazenamento, variando de 19,1 a $23,6 \%$ no tempo zero e de 19,8 a $22,1 \%$ após o armazenamento. Os teores de gordura (Tabela 4) também apresentaram pequenas variações $(41,7$ a $47,7 \%$ no tempo zero e de 45,0 a $48,4 \%$ após quatro meses). Estas variações podem ser devidas a erros na amostragem ou à absorção diferencial de gordura pelas amêndoas durante a fritura, em função do tamanho e formato irregular das mesmas e características dos óleos utilizados.

\section{TABELA 3 - TEOR DE PROTEÍNA (\%) EM AMÊNDOAS DE CASTANHA DE CAJU FRITAS EM DIFERENTES ÓLEOS}

\begin{tabular}{ccccc}
\hline $\begin{array}{c}\text { Tempo } \\
\text { (meses) }\end{array}$ & $\begin{array}{c}\text { Gordura Vegetal } \\
\text { Hidrogenada }\end{array}$ & $\begin{array}{c}\text { Óleo de } \\
\text { Algodão }\end{array}$ & $\begin{array}{c}\text { Óleo de } \\
\text { Babaçu }\end{array}$ & Óleo de Soja \\
\hline 0 & $20,2 \mathrm{~A}$ & $19,1 \mathrm{~B}$ & $19,5 \mathrm{~B}$ & $23,6 \mathrm{~A}$ \\
4 & $19,8 \mathrm{~B}$ & $22,1 \mathrm{~A}$ & $20,9 \mathrm{~A}$ & $20,1 \mathrm{~B}$ \\
\hline
\end{tabular}

Em cada coluna, médias seguidas pelas mesmas letras não diferem significativamente ao nível de $5 \%$ pelo teste de Tukey. 


\section{TABELA 4 - TEOR DE GORDURA (\%) EM AMÊNDOAS DE CASTANHA DE CAJU FRITAS EM DIFERENTES ÓLEOS}

\begin{tabular}{ccccc}
\hline $\begin{array}{c}\text { Tempo } \\
\text { (meses) }\end{array}$ & $\begin{array}{c}\text { Gordura Vegetal } \\
\text { Hidrogenada }\end{array}$ & $\begin{array}{c}\text { Óleo de } \\
\text { Algodão }\end{array}$ & $\begin{array}{c}\text { Óleo de } \\
\text { Babaçu }\end{array}$ & Óleo de Soja \\
\hline 0 & $47,6 \mathrm{~A}$ & $42,1 \mathrm{~B}$ & $47,7 \mathrm{~A}$ & $41,7 \mathrm{~B}$ \\
4 & $48,4 \mathrm{~A}$ & $45,0 \mathrm{~A}$ & $47,2 \mathrm{~A}$ & $45,4 \mathrm{~A}$ \\
\hline
\end{tabular}

Em cada coluna, médias seguidas pelas mesmas letras não diferem significativamente ao nível de $5 \%$ pelo teste de Tukey.

O índice de peróxido (Tabela 5) apresentou valores altos sob o ponto de vista oxidativo, variando de 11,9 a 24,6 no tempo zero. Estes valores aumentaram durante 0 armazenamento para todos os tratamentos, com exceção daquele em que se utilizou óleo de algodão. O índice de peróxido obtido após 4 meses de armazenamento indica que o óleo de algodão e a gordura vegetal hidrogenada são os mais indicados para o processo de fritura das amêndoas, quando se analisa este parâmetro isoladamente.

\section{TABELA 5 - ÍNDICE DE PERÓXIDO (meq/1000g de óleo) EM AMÊNDOAS DE CASTANHA DE CAJU FRITAS EM DIFERENTES ÓLEOS}

\begin{tabular}{ccccc}
\hline $\begin{array}{c}\text { Tempo } \\
\text { (meses) }\end{array}$ & $\begin{array}{c}\text { Gordura Vegetal } \\
\text { Hidrogenada }\end{array}$ & $\begin{array}{c}\text { Óleo de } \\
\text { Algodão }\end{array}$ & $\begin{array}{c}\text { Óleo de } \\
\text { Babaçu }\end{array}$ & Óleo de Soja \\
\hline 0 & $11,9 \mathrm{~B}$ & $24,6 \mathrm{~A}$ & $23,4 \mathrm{~B}$ & $24,1 \mathrm{~B}$ \\
4 & $14,1 \mathrm{~A}$ & $14,9 \mathrm{~B}$ & $25,3 \mathrm{~A}$ & $30,6 \mathrm{~A}$ \\
\hline
\end{tabular}

Em cada coluna, médias seguidas pelas mesmas letras não diferem significativamente ao nível de $5 \%$ pelo teste de Tukey.

Os valores observados para o índice de acidez (Tabela 6) variaram de 1,39 a 1,70 no tempo zero e de 1,99 a 2,53 após 4 meses de armazenamento. Estes valores são baixos, indicando pequena hidrólise nas amêndoas, no entanto, para as amostras fritas em óleos de algodão e soja, pequenas alterações já podiam ser percebidas. 


\section{TABELA 6 - ÍNDICE DE ACIDEZ (mgKOH/g óleo) EM AMÊNDOAS DE CASTANHA DE CAJU FRITAS EM DIFERENTES ÓLEOS}

\begin{tabular}{ccccc}
\hline $\begin{array}{c}\text { Tempo } \\
\text { (meses) }\end{array}$ & $\begin{array}{c}\text { Gordura Vegetal } \\
\text { Hidrogenada }\end{array}$ & $\begin{array}{c}\text { Óleo de } \\
\text { Algodão }\end{array}$ & $\begin{array}{c}\text { Óleo de } \\
\text { Babaçu }\end{array}$ & Óleo de Soja \\
\hline 0 & $1,64 \mathrm{~A}$ & $1,39 \mathrm{~B}$ & $1,70 \mathrm{~A}$ & $1,62 \mathrm{~B}$ \\
4 & $1,99 \mathrm{~A}$ & $2,27 \mathrm{~A}$ & $1,99 \mathrm{~A}$ & $2,53 \mathrm{~A}$ \\
\hline
\end{tabular}

Em cada coluna, médias seguidas pelas mesmas letras não diferem significativamente ao nível de $5 \%$ pelo teste de Tukey.

$\mathrm{Na}$ avaliação sensorial (ordenação/preferência) não foram detectadas preferências significativas $(p \leq 0,01)$ para as amostras iniciais (tempo zero) pelo teste de "Friedman" (Quadro 1). Após 4 meses de armazenamento observou-se preferência ( $p \leq 0,01$ ) pelas amêndoas fritas em gordura vegetal hidrogenada (Quadro 2).

\section{QUADRO 1 - DIFERENÇA ENTRE TOTAIS DE ORDENAÇÃO SENSORIAL PARA AMÊNDOAS DE CASTANHA DE CAJU FRITAS EM DIFERENTES ÓLEOS (TEMPO ZERO)}

\begin{tabular}{|c|c|c|c|c|c|}
\hline Amostras & & $\begin{array}{c}\text { Óleo de } \\
\text { algodão }\end{array}$ & $\begin{array}{c}\text { Óleo de } \\
\text { babaçu }\end{array}$ & $\begin{array}{c}\text { Óleo de } \\
\text { soja }\end{array}$ & $\begin{array}{c}\text { Gordura veg. } \\
\text { hidrogenada }\end{array}$ \\
\hline $\begin{array}{c}\text { Total das } \\
\text { notas }\end{array}$ & 92 & 89 & 82 & 87 \\
\hline $\begin{array}{c}\text { Óleo de } \\
\text { algodão }\end{array}$ & 92 & & $3 \mathrm{~ns}$ & $10 \mathrm{~ns}$ & $5 \mathrm{~ns}$ \\
\hline $\begin{array}{c}\text { Óleo de } \\
\text { babaçu }\end{array}$ & 89 & & & $7 \mathrm{~ns}$ & $2 \mathrm{~ns}$ \\
\hline $\begin{array}{c}\text { Óleo de } \\
\text { Soja }\end{array}$ & 82 & & & & $5 \mathrm{~ns}$ \\
\hline $\begin{array}{c}\text { Gordura veg. } \\
\text { Hidrogenada }\end{array}$ & 87 & & & & \\
\hline
\end{tabular}

ns = não há diferença significativa entre as amostras ao nível de 5\% de significânica. 


\section{QUADRO 2 - DIFERENÇA ENTRE TOTAIS DE ORDENAÇÃO SENSORIAL PARA AMÊNDOAS DE CASTANHA DE CAJU FRITAS EM DIFERENTES ÓLEOS (APÓS 4 MESES DE ARMAZENAMENTO)}

\begin{tabular}{|c|c|c|c|c|c|}
\hline Amostras & & $\begin{array}{l}\text { Óleo de } \\
\text { algodão }\end{array}$ & $\begin{array}{l}\text { Óleo de } \\
\text { babaçu }\end{array}$ & $\begin{array}{c}\text { Óleo de } \\
\text { soja }\end{array}$ & $\begin{array}{l}\text { Gordura veg. } \\
\text { hidrogenada }\end{array}$ \\
\hline & $\begin{array}{c}\text { Total das } \\
\text { notas }\end{array}$ & 79 & 73 & 72 & 106 \\
\hline $\begin{array}{l}\text { Óleo de } \\
\text { algodão }\end{array}$ & 79 & & $6 \mathrm{~ns}$ & $7 \mathrm{~ns}$ & $27 *$ \\
\hline $\begin{array}{l}\text { Óleo de } \\
\text { babaçu }\end{array}$ & 73 & & & $1 \mathrm{~ns}$ & $33 *$ \\
\hline $\begin{array}{c}\text { Óleo de } \\
\text { soja }\end{array}$ & 72 & & & & $34 *$ \\
\hline $\begin{array}{l}\text { Gordura veg. } \\
\text { hidrogenada }\end{array}$ & 106 & & & & \\
\hline
\end{tabular}

* amostras diferem entre si ao nível de $5 \%$ de significância. ns = não há diferença significativa entre as amostras ao nível de $5 \%$ de significânica.

\section{CONCLUSÃO}

O aumento rápido da umidade das amêndoas evidencia a necessidade de se utilizar embalagens com maior barreira ao vapor de água, de maneira que não se coloque em risco a estabilidade microbiológica das amêndoas e nem se promova alterações de textura que poderão causar rejeição do produto.

Os valores de índice de peróxido indicaram que o óleo de algodão e a gordura vegetal hidrogenada obtiveram melhor desempenho no armazenamento das amêndoas de castanha de caju. No entanto, de acordo com o índice de acidez, pequenas alterações hidrolíticas foram observadas nas amêndoas fritas em óleo de algodão. Desta forma, os melhores resultados físico-químicos foram observados quando as amêndoas de castanha de caju foram fritas em gordura vegetal hidrogenada.

A avaliação sensorial confirmou os resultados físico-químicos, visto que após o armazenamento de 4 meses, as amêndoas de castanha de caju 
fritas em gordura vegetal hidrogenada foram as preferidas pelos provadores.

\begin{abstract}
The influence of the frying oil type in the stability of processed cashew nut kernels were evaluated. Four types of oils (soybean, cotton seed, babassu and hydrogenated soybean oil) were employed with fixed temperature and frying time. Processed cashew nut kernels were evaluated in relation to its physical chemical characteristics just after processing and at four months of storage (polyethylene packages, room temperature), aiming to verify the oil type effect in the aging of the products. Sensory ranking/preference tests were also used with objective to verify which oil were preferred. Results indicated that hydrogenated soybean oil is more adequate for cashew nut kernels frying.
\end{abstract}

\title{
REFERÊNCIAS
}

1 AOAC. Association of Official Analytical Chemistry. Official methods of analysis of the AOAC International. $11^{\text {th }}$ ed. Washington, 1992. $1115 \mathrm{p}$.

2 AOCS. American Oil Chemists' Society. Official methods and recommended practices of the AOCS. $3^{\text {rd }}$ ed. Champaign, 1988.

3 CRISÓSTOMO, J. R.; LEITE, L. A. S.; PEREIRA FILHO, J. E.; PAULA PESSOA, P. F. A. Avanços tecnológicos e desafios atuais do agronegócio caju no Nordeste do Brasil. In: TALLER DESAROLLO AGROINDUSTRIAL DE LA GOMA, CASTAÑA Y OTROS PRODUCTOS CON POTENCIAL DE LA AMAZONIA BOLIVIANA, Guayaramerin Beni (Bolívia), 11 a 14 dez. 1995. Anais.... Guayaramerin Beni (Bolívia), 1995. p.1-7.

4 EDIBLE nut market report. Rotterdam: Man Producten, Mar. 1998.

5 FRANKEL, E. N. Volatile lipid oxidation products. Progress in Lipid Research, v.22, n.1, p.1-33, 1982.

6 FRANKEL, E. N. Lipid oxidation: mechanisms, products and biological significance. Journal of the American Oil Chemists' Society, Champaign, v. 61, n. 12, p. 1908-1917, Dec. 1984.

7 HAMILTON, R. J. The chemistry of rancidity in foods. In: ALLEN, J. C.; HAMILTON, R. J. (Eds.). Rancidity in foods. London: Applied Science, 1983. p. 1-20.

8 LABUZA, T. P. Kinectics of lipid oxidation in foods. CRC-Critical Reviews in Food Technology, Cleveland, v. 2, n. 3, p. 355-405, Oct. 1971. 
9 MEILGAARD, M.; CIVILLE, G.V.; CARR, B.T. Sensory evaluation techniques. Florida: CRC, 1987. v. 2.

10 INSTITUTO ADOLFO LUTZ. Normas analíticas do Instituto Adolfo Lutz: métodos químicos e físicos para análise de alimentos. 3. ed. São Paulo, 1985. 533 p.

11 SANTOS, V. P. M. A cultura do cajueiro no Nordeste do Brasil. Fortaleza: Banco do Nordeste do Brasil, 1988. Cap. 2, p. 43-61. 